\title{
Cooperation and Politeness in Television Discourse
}

\author{
Grace O. Olutayo ${ }^{1, *}$ \\ ${ }^{1}$ Department of English, Faculty of Humanities, Bowen University, Nigeria \\ *Correspondence: Department of English, Faculty of Humanities, Bowen University, Nigeria. E-mail: \\ graceolutayo@yahoo.com
}

Received: August 25, $2015 \quad$ Accepted: October 23, 2015 Online Published: November 23, 2015

doi:10.5430/wjel.v5n4p1 URL: http://dx.doi.org/10.5430/wjel.v5n4p1

\begin{abstract}
This paper seeks to examine instances of cooperation and politeness in television discourse with emphasis on television talk shows in Nigeria. Several works have been examined using the cooperative principle and politeness theory, but little has been done on television discourse. This work thus intends to use the talk show genre with the aim of calling the attention of researchers to the viability of the genre. The theoretical framework adopted for this study is Grice's cooperative principle and Levinson's Politeness' theory. Three popular Nigerian TV talk shows were sampled for the study. Four episodes were selected from each for analysis. Our analysis reveals that while the hosts and participants sought to cooperate and exhibit politeness in the discourse, there were several instances of flouting and hedging of conversational maxims and face threatening acts.
\end{abstract}

Keywords: Conversational maxims; Talk show genre; Flouts; Hedges and face threatening acts

\section{Introduction}

For a conversation to run smoothly and achieve the desired goal participants must have a shared understanding of the discourse and they must agree to cooperate with one another by respecting each other's view and allowing interlocutors to take their turns in the conversation. To successfully conduct a conversation, participants must display a willingness and ability to collaborate (Gumperz, 1990). Successful conversation yields, for each participant, a degree of relational and interactional satisfaction. Successful verbal communication requires one to be able to identify and satisfy the needs of one's fellow conversant. To do this, one must be able to take the perspective of the other and adapt one's language to reflect that perspective (Spekman, 1983). At the beginning of a conversation, participants often frame the event. That is, they make clear to each other the intended nature of the conversation-to-be. All conversations contain phatic communication; some conversations are also purposeful in that the participants have a defined goal, whether to impart information, formulate a plan or advocate a change. In a purposeful meeting, every conversational move ideally contributes to the overall goal as set by the participants.

In order to begin a conversation, participants must form a relationship, and to do this they must in some sense be of the same order. Spekman (1983) says there is a need to establish a temporarily-shared reality among participants. "Participants, to some degree, must agree upon a world-view, a cosmology" (Goffman 1986:28). Common ground - a set of propositions which make up the contextual background for the utterances to follow- must be established (Spekman, 1983:168).

Ideally, conversation involves each participant being interested in what the other has to say, each participant being a patient and emphatic listener, and following Grice's Maxims. In the real world, however, these conditions are not often present. For example, one conversational participant may attempt to monopolize resource (Roloff and Douglas, 1985:162). Participants who feel slighted may react by withdrawing, resisting, or rebelling, for example, by being ironic. Violations of reciprocity are sources of dissatisfaction within groups, and are a major cause of group disintegration (Ibid, 1985: 170).

Regardless of the nature of a conversation, participants must feel comfortable with each other on the social, personal, and feeling levels for there to be any chance for information to be imparted successfully. That is, one needs to feel good about the speaker in order to be able to want to take in any of what he or she has to say. In television talk shows which we intend to examine in this study, participants on almost the same rung of the ladder are often brought together so that 
there would be smooth interaction among them. It is the duty of the moderator of the programme to create a conducive and comfortable environment for the participants so that the aim of the talk could be achieved.

\section{Literature Survey}

\subsection{The Cooperative Principle}

The Cooperative Principle was introduced by Grice (1975). It was related to the smooth running of conversations. Grice believed that for a conversation to run smoothly, participants must follow certain social conventions. The Cooperative Principle simply states that make your conversational contribution such as is required, at the stage at which it occurs, by the accepted purpose or direction of the talk exchange in which you are engaged. (Grundy, 2000:74).

Grice highlights four maxims that should be observed by participants, the first maxim is of quantity, which states that speakers should be as informative as is required. They should not give too little or too much information to their hearers. The second maxim is the maxim of quality. It states that speakers are expected to be sincere, to be saying something that they believe corresponds to reality. They should not say anything that is false or that for which they lack evidence. The third maxim is that of relation. Speakers should say something that is relevant to what had been said before. The fourth maxim is of manner. It says that speakers should be brief and orderly. They should avoid obscurity and ambiguity.

Non observance of these maxims in conversation could be regarded as flouts, violation or hedges. Instances of flouts, violations and hedges of cooperative maxims are discussed below.

\subsection{Flouting the Maxims}

It is believed that any participant that does not follow these maxims during the course of a conversation, but expects the hearers to appreciate the meaning implied has flouted the maxims. This implies that if a speaker gives too little, or too much information in his/her speech, he/she has flouted the maxim of quantity e.g.

\section{Example 1}

A. Where is your mother?

B. She is not at home; she has gone to the market and won't be back until 6 p.m.

In the hypothetical example above, $\mathrm{B}$ has given more information than is required. She would have given the appropriate information if she had said just where her mother was; e.g. 'she is in the market'.

A speaker could also be said to have flouted the second maxim which is the maxim of quality when he/she says something for which he/she has no evidence. This could be done in several ways: s/he may simply say something that does not represent what $\mathrm{s} / \mathrm{he}$ thinks by exaggerating, using an hyperbole, a metaphor, an irony or a banter.

A speaker flouts the maxim of relation when s/he expects that the hearers will be able to imagine what the utterance did not say, and make the connection between her utterance and the preceding one (s) (Cutting, 2003).

When a speaker is not clear in her utterance or when she is deliberately ambiguous, she is said to have flouted the fourth maxim which is the maxim of relation.

\subsection{Violating the Maxims}

A speaker can be said to 'violate' a maxim when s/he knows that the hearer will not know the truth and will only understand the surface meaning of the words. She intentionally generates a misleading implication (Thomas, 1995). In maxim violations, a speaker deliberately supplies insufficient information, says something that is insincere, irrelevant or ambiguous, and the hearer wrongly assumes that she is cooperating. When a speaker does not want the hearer to know the truth, he could withhold some part of the information from him deliberately by violating the maxim of quality.

Other ways of failing to fulfill a maxim as given by Grice (1975) are: to infringe it and to opt out. A speaker infringing a maxim or opting out of a maxim is not implying something different from the words or being intentionally misleading (Cutting 2002:41). A speaker may infringe a maxim when he fails to observe it because of his imperfect linguistic performance.

\subsection{Hedging Maxims}

Maxims are hedged when a speaker tells the listener the extent to which he is abiding by the maxims. This could be done through metalingual glosses e.g. "What's your name by the way", "by the way" suggests to the listener that the 
question is not relevant to the conversation and the speaker knows it.

Example 2

"All I know is that we shall be writing a test tomorrow."

Example 3

"They say men are dangerous."

In the examples above, 'all', 'know' and 'They say' are metalingual glosses. They serve as comments on the extent to which the speaker is abiding by the conversational maxims. While the first example hedges the maxim of quantity, it explicitly advises the listener that the information she has given is limited, as she doesn't seem to know more than this.

"They say men are dangerous" hedges the maxim of quality, as the speaker does not seem to have any evidence to support her claim. This, she makes clear to the listener by using the metalingual gloss. 'They say'.

\subsection{Politeness Principle}

Non-prescriptive, true politeness can be thought of as the techniques people use to avoid being offensive, embarrassing, aggressive or presumptuous in conversation (Sisson, 2007). In their seminal work on politeness, Brown and Levinson (1987) define politeness as an attempt by the speaker to preserve the self-esteem or face of both speaker and the hearer.

Brenan and Ohaneri (1999:228), cited in Sisson (2007), write that politeness indicates “information about the speaker's commitment to particular propositions and their willingness to have this information modified by a partner". People express their commitment to the content of their utterance through facial expressions and gestures as well as through linguistic choices and mannerisms, such as intonation, word choice and syntax. True politeness can be communicated in many different ways. In this work, we are mainly concerned with linguistic politeness which comes in many forms.

Brown and Levinson identify two super-classes of politeness namely positive and negative politeness. Positive politeness relates to the speaker's desire for the listener to share the same perspective, emphasizing their commonalities. Negative politeness, on the other hand, focuses on respecting the differences between the speaker and the hearer, and granting them autonomy and freedom from obligation to each other (Sisson, 2007).

However, Brown and Levinson's characterization of politeness strategies as either positive (paying attention to the other's face needs) or negative (ensuring that the other is not imposed on) has been modified by Scollon and Scollon (1995). The Scollons assert that it is preferable to refer to such strategies as 'involvement' or 'distancing strategies' as this terminology avoids the implicit evaluation contained in Brown and Levinson's terms. They also suggest that 'the concept of face has built into it both aspects: involvement and independence must be projected simultaneously in any communication' but they go on to argue that 'the reason involvement and independence are in conflict is that emphasizing one of them risks a threat to the other' (Scollon and Scollon, 1995:38).

\subsection{Culture and Politeness}

Culture has a great impact on how politeness is communicated and negotiated (Sisson, 2007). Pan (2000) suggests that the theory of face proposed by Brown and Levinson (1987) may not be as universal as they suggest, particularly for cultures which are less individual-centred than Western culture. She claims that politeness is more situational for the Chinese than it is for Americans and that face management does not always adequately explain politeness behaviour. Likewise in many Nigerian cultures, politeness is more situational and face management does not always indicate politeness. According to Odebunmi (2003), in Nigerian cultures, the Hausa and the Yoruba operate at two extremes in terms of politeness. While the Hausa are blunt in their descriptions of persons and phenomena, including deformities, the Yoruba are reserved. A Yoruba man is essentially euphemistic in his language usage when issues that border on the psycho-social and emotional aspects of co-participants are affected. Thus if these cultural peculiarities, conventions and associations are related to world cultures, the politeness principle has some affiliation with euphemistic usage of language (Odebunmi, 2005).

\subsection{Concept of Face and the Theory of Politeness}

The concept of face has come to play an important role in politeness theory. Brown and Levinson, for example, have chosen it as the central notion for their study of Universals in language usage and politeness phenomena $(1978,1987)$. They have paraphrased 'face' as the public self-image that every member wants to claim for himself (1978), but obviously they prefer 'face' to 'public self-image', for throughout their text, they almost exclusively use the term 'face', only occasionally mentioning 'public self- image'.

Brown and Levinson claim that they have derived the notion of 'face' from Ervin Goffman and 'from the English folk 
term which ties face up with notions of being embarrassed or humiliated, or "losing face" (1978:66). In the processes of their analysis, they have come to distinguish between negative and positive face which they have defined as follows:

a) Negative face: the basic claim to territories, personal preserves, rights to non-distinction-i.e. to freedom of action and freedom from imposition.

b) Positive face: the positive consistent self-image or 'personality' (crucially including the desire that this self-image be appreciated and approved of) claimed by interactants (1978:66).

Odebunmi (2003) opines that face exists in kinds. The first is respect or deference which operates in a situation of social distance, for example, the relationship between a messenger and his boss in an office or respect of age differential between a child and his father. The second kind of face is friendliness, camaraderie or solidarity which occurs in social closeness this kind of face is found between equals.

\subsection{Face Theory}

Goffman defined face as the "positive social value a person effectively claims for himself by his or her self-representation" (1967:5). Face includes the value to a person of his or her public image, reputation, and status vis-a-vis other people in an interaction. A person's face then is the social value of who and what they hold themselves to be. For an interaction to proceed smoothly, the parties must allow one another to maintain face. In addition to negotiation, face maintenance affects communication strategy (Linde, 1988; Leichty\& Applegate, 1991; Lee, 1993; Carson \& Cuppach, 2000; Tracy, 2002), cross-cultural interaction (Ting-Toomey \& Cocroft, 1994; Lindsley \& Braithwaite, 1996; Earley, 1997) and relationships (Melts, 1997).

Face can be said to be social. This implies that the dynamics of face maintenance are determined not only by who and what the individual hold himself/herself to be, but also by how others respond to this presentation (Goffman, 1967). Thus, face is a social construct, just as much a property of the social interaction as an attribute of the individual. Maintaining face, therefore, requires the cooperation of others. Other people can, by their verbal and non-verbal behavior, uphold or threaten an individual's face, accord or deny the positive social value claimed by the individual (White, et al 2004:103).

Face is not necessarily positive, nor is it the same across all situations. This means that face can change from one situation to the next, and that face can have more value in some situations than others. For example, a teacher might rely on a colleague to uphold her face as a competent teacher in front of her students, and later count on that colleague to uphold her face as an entertaining dinner companion. Telling a story of how she lost her lesson note could threaten her face in the classroom but uphold her face at a dinner with her friend. A speaker's value might have more value when one of the participants is someone she particularly wishes to impress. The positive social value of an individual's face then depends not only on the cooperation of others, but also on the precise social situation (White, et al 2004:103).

\subsection{Threats to Face}

Due to the direct link between face and self-esteem, people are often motivated to have their face upheld, and feel thwarted when their face is not upheld, or when it is threatened. People respond to face threats with negative emotion (Goffman, 1967:6), ranging from slight discomfort or embarrassment, to mild annoyance, anger, and outright hostility (e.g., Andersson \& Pearson, 1999; Pearson, Anderson \& Porath, 2000). It is assumed that the greater the threat to face, the more intense the emotional response. Carson and Cupach (2002) report a linear relationship, $r=.82$, between the degree of face threat perceived by an individual and the level of anger he or she feels. In fact, some emotions may be uniquely connected to face threats (White, et al 2004). Keltner and colleagues (Keltner \& Buswell, 1996, 1997; Keltner \& Haidt, 1999; Keltner \& Anderson, 2000) suggest that embarrassment is a distinct, functional emotion felt in response to a threat to social status what we would call a face threat. When an individual's face is met, i. e. when his/her desires are approved, respected and appreciated, we have instances of Face Saving Acts (FSAs). But when these do not happen, the speaker/listener's face is said to be threatened, thus we have Face Threatening Acts (FTAs).

\section{Methodology}

Three Nigerian television talk shows namely: "Patito's Gang", "New Dawn with Funmi Iyanda" and "Inside Out" were purposively selected for this study. Four episodes from each talk show were chosen for analysis from a number of episodes recorded via the television. The episodes were played back a number of times and later transcribed to elicit instances of cooperation and politeness. 


\section{Analysis}

\subsection{The Nature of Grice's Maxims in the Talk Shows}

Here, we examined instances of flouts of the cooperative maxims. Despite the cooperation enjoyed by all participants, we still had some maxims which were flouted during discussions. We would take the discussions of these flouts one after the other.

\subsubsection{Quantity maxim}

Quantity maxims are usually flouted in television talk shows. It was observed in our study that before a participant gave his /her response, he would have given some preambles through story telling or relating his contribution to what the last speaker said. Thus we had about $70 \%$ of quantity maxim flouts in our study. Most times participants gave more information than was required as we found in the excerpts below:

\section{Excerpt 1-ND4}

1. TH: Now having read this book I know that the significance of this place to you. Some of the stories about how it was built, the friends rolling in it and all of that. When you are coming in here, when you drive here, describe to us your feelings every time you are coming here and does it change from one point to the other, giving your many many experiences and interventions on things that have occurred to you each time you drive to this place.

2. PP: Hen, hen! It is on one hand, an easy question and on the other hand, a difficult one because it is impossible to jump the depth and responses each time I enter the last stretch into this place... it's the outside world (.3) is like it does not exist and the problem is that tearing myself away from them each time I come here.

3. TH: how did you find this place or did it find you?

4. PP: (laughs). Well, when I left University of Ife, I said good bye as far as I was concerned to teaching on a regular basis and I began looking for a very quiet spot to fulfil that long that had always been denied me, you know, so many years, many decades. Then I searched in my paternal home and I searched around here, my maternal home and then when I was hunting in various parts of the country I remembered once I found a place in Kwara State. In Jos, I saw a place where I'll build the retreat slowly. Finally, I came to this place; it was an extension of the housing estate but the actual space was marked by Ogun state... what exactly I do is to construct a stretch and nobody lives here, I got a land surveyor or whatever you called it. I was also looking for a stream. I wanted to be independent. I wanted to be sure I wasn't relying on NEPA as it was over the time and I need water supply from the central. There is a stream at the very end of the land and traced it backward until I found the source of the spring coming out of land and I said that is it. The next thing is to call a friend of mine Dr. Agunloye to come and use his technique to see if I can sink a bore hole because of that stream and there must be some underground water source. Once he said yes, I began...

From the two responses given by the PP above, it could be seen that the maxim of quantity was flouted as the information given was more than what TH required. The first question was about how the guest felt each time he came home; before he gave the answer, he first gave the description of the question. In the second response, he started his answer by referring to when he left the teaching profession, and how he went about searching before he found the place instead of going straight to the answer. The question did not have anything to do with when he left the teaching profession and why he left. However, TH could not tell him that he did not go straight to the point; she accepted the flout as an attempt to spice up the discussion. She also had to cooperate with the guest as she knew that he would still come back to the issue at hand. This is one of the factors that are responsible for elongation of talk shows and inability of the discussants to conclude on the topic.

\section{Excerpt 3-IO4}

87. TH: before we round up (sic) let me, let me take the last comment. I have to really, we're done, we've really overshot our time.

88. SA8: now we have to locate everything in our peculiar circumstances in our value system. Today Nigeria ranks the second hem... most corrupt country in the world...

89. PP3: third, third. 
90. SA8: okay third we have been promoted (laughter)

91. PP3: is good, is good, is good for us.

92. SA8: that we are not lacking that because of our population but because of our love for money, this thing must be located in the people's value system(?) Romance should not be a function of hem the pocket, it should be a function of the heart

93. PP2: thank you.

94. SA8: but hem as it is today, we have em money is our determinant factor. In anything we do in Nigeria, if you are going to the, to join the police force people are thinking of how much you are going to get from bribe not how much you are going to get as a policeman...

SA8 in the excerpt above gave more information than was required. He started by making reference to our value system and did not end until he said that money is the determinant factor of everything we do in Nigeria. His preambles gave room for the interruptions at Turns 90, 92 and 94. Viewers who were not careful might lose the trend of what SA8 was saying. This indicates that flouts of quantity could contribute to loss of the message in a participant's contribution.

\subsubsection{Quality Maxim}

This maxim was always obeyed in TV talk shows, no untrue statement was observed except for exaggerations and contrary opinions. The truth of what the host and the participants said here was important as it determined the number of viewers of the programme to a large extent. The integrities of the invited guests were also at stake. If the viewers found out that truth was not a feature of a programme, the programme becomes unpopular and viewers would dwindle. Sometimes the truth may be couched to avoid inciting the public against the State.

\section{Excerpt 4-PG1}

139. PP6: Under invasion

140. PP7: $\quad$ Excuse me... Excuse me...

141. PP8: The President was too sentimental on this issue...

142. PP9: $\quad$ Sorry. All the people here

143. PP8: He was too sentimental on that

144. PP10: A state of emergency with regard to Section 305, he should not fold his arm and watch so declaring a State of Emergency in Plateau State is just to protect life

145. TH: Hold on

146. PP10: It's unfortunate that Plateau State was used as the scape goat to seek for the fact that you know that he did this thing to maintain law and orderliness in the state. Then in so doing, because instead of the destruction reckless destruction of life and property to start going on in a particular state...

147. PP11: Question, question, aren't there other states that ought to have...

148. PP6: I think there are many states where...

149. PP12: He had an ulterior motive...

150. PP6: $\quad$ State of Emergency .... power and declare State of Emergency

Here, the participants did not shy away from saying the truth; they were not bothered that they would be seen by government officials while speaking out their minds. These types of courageous expressions give talk shows a lot of credibility as viewers would always be interested in where the truth is said without blinking an eye.

\subsubsection{Relation Maxim}

Few instances (about $30 \%$ ) of non-observance of the maxim of relation were observed in the talk shows examined in this study. Participants tried to ensure that their contributions were related to the propositions made by other speakers. Sometimes, flouts of relation maxims could arise out of sentiments or emotional outburst. For example:

\section{Excerpt 5-IO1}

29. TH: Wole, you have to say something, Wole, you have to say something (calling on another speaker). 
30. Wole: Now, let's start from this; we are talking about policeman, culture or no culture maybe there's response or no response. I repeat Nigerian Police force, the culture they have is different is different from the culture advanced nations have. There is a ba ....

The flout in the excerpt above was as a result of sentiment. The participant was not being objective in his contribution so he had to bring in the issue of culture in his attempt to protect the Nigerian policemen. The indication here is that flouts of relation could be used by participants to hedge a maxim or cover the truth.

\section{Excerpt 6-ND3}

13. TH: What change? Was there a single thing that change...

14. PP: Yes, a singular thing is this... I asked myself if I didn't do these, what opportunities and what hope was I leaving for my children. If they ask me down the line that 30 years time Daddy, where were you? What did you do? I want to be able to look back and point to my own contributions and I think in any event this is significant, it comes from these. This is the responsibility of this generation. We are the ones raising families, we are the ones buying new homes, we are the ones looking to the future, having children in schools; it can't be our parents anymore, they've done their bit for us and we must show some appreciations (.sic) by taking the initiatives, by taking responsibilities for our actions.

The response of PP above was a flout arising out of emotional outburst. The content of his contribution did not seem to have anything to do with the question TH asked.

\section{Politeness in Talk Show}

Politeness principle here is examined under positive and negative politeness. Instances of Face Threatening Acts (FTAs) are examined. FTA with redress is taken to mean positive politeness (when information is given indirectly) and FTA without Redress means negative politeness (when information is given directly without redressing it).

\subsection{FTA without Redress}

\section{Excerpt 7-PG1}

27. PP4: Well beyond all these, what we must understand is that we need to retrace our step. If, we feel to continue to bring military into democracy, these are the results we are going to get. Until we actually democratize Nigeria, we will begin to have the military insurgence (points up) into the democratic polity process. Ok? And there is no way you can do it. Once you are a military man, you've never retired and we are going to see this thing coming up from time to time. Obasanjo has kept on doing this all the time.

28. TH: all the time

29. PP4: and there is no way because after a while he says who are you? And rather than bring the gun, he brings his military might and he will deplore it immediately. Tell me, there is no time this man has subjected himself to what democracy is all about, you know,...

PP4 here used FTA without redress. He addressed the former president, Olusegun Obasanjo directly without couching his criticism. The essence of this was to say the truth as it was and to make the addressee see reason to change his mind about the controversial declaration of a state of emergency in Plateau state.

\section{Excerpt 8-ND2}

96. TH: em... I have a headache. Okay what do you think is happening here?

97. PP: I think ehn, all these dreams, I have an opinion about dreams, you dream from what you think about. If you are desperate about money, you dream of money. You dream from God and the devil, that is my opinion. You have to know what is troubling you. I think his girlfriend, the Ibo girl is a troubled person, as in trouble by the fact that she is marrying into Yoruba; you see when you marry another human being it caused you his own bondage talk less of when it is inter-tribal; you will even have more problem but some people have natural fear-would they accept me? The language thing, would the mother like me if I don't cook their kind of soup? I think he is also afraid of buying yams and building houses as they claim you must do if you want to marry Ibo.

98. TH: Ah! Is that true? Where is Abigail \{looking for supports\}

99. PP: it's an allegation

100. TH: who is an Ibo girl here, it's not true 
101. PP: They say you must build a house for your father - in - law and you must buy all the new yams in the town. May be this man is afraid because he is listening to hear sameness instead of asking his girlfriend show me the list if such exists. Now he said there is somebody in his house that he has the likeness of a sister for. To me, he is not telling the truth because he has already been dreaming that the girl is kissing him, what kind of dream is that. Then she comes and says...

In this therapeutic talk show, the guest did not pamper the writer at all. He went straight to the point by stating what he thought the problem of the man was and what he was running away from. The writer who presented the problem would have seen himself just as he was and that would have put a paid to the supposed problem. Most times, FTA without redress would enable interlocutors solve their problems more easily when the listener(s) is brought to the knowledge of who he is and where the solution to his problem lies.

\subsection{FTA with Redress (Positive Politeness)}

This occurred when a speaker saved the listener/participant's face or reduced the threat to his face by talking indirectly about his problem. This could be done through euphemisms or other indirect expressions.

\section{Excerpt 9}

7. TH: I just want to, I want to get another view, because if we start the discussion now it won't end. Dr. Leke Pitan, I... I... I... want to if you would like to add anything to that

8. PP2: haa yes, haa apart from those who eeh, who have the person he has just described are those they say have learning difficulties that is the terminology we use now but beyond that we also have those who are visually impaired

10. TH: $\quad$ that like the blind

11. PP2: $\quad$ no we don't use that terminology

12. TH: $\quad$ am sorry

13. PP2 they say visual impairment

14. TH: $\quad$ I say I am going to get educated here

15.PP2: we don't say somebody is deaf we say he has hearing impairment, we don't say somebody is dumb we say he has speech difficulty and so on; alright even though those who have had polio or something in you say they have physical impairment, so all those people too can be put in regular schools

12. TH: $\quad$ rather than creating a school for the visually impaired

From the excerpt above, we can see that those who are physically challenged are referred to through indirect expressions such as 'visually impaired', 'hearing impaired', and 'speech difficulty' and so on. These lexical items were used to indicate positive politeness. The disabilities of these people were not mentioned directly to save their faces.

\subsection{Polite Expressions}

Several polite expressions were used by the hosts and the participants in our study. Some of the titles of the talks themselves were polite as the hosts sought to couch their expressions in order to save the face of their viewers. We had topics such as "Inclusive Education" and "Physical Challenges".

\section{Excerpt 10-PG3}

1. TH: We are back. This is Patito's gang. Today, a really important subject matter; we are looking at Physical Challenges. Handicaps that many of our citizens are challenged (.3) they can be handicaps in term of visual impairment, in terms of hearing, in terms of the ability to speak, or they can be physical handicaps in terms of well bone structure and all of that. Many, many of our citizens have to live with these challenges. In many parts of the world a special attention is paid (.) in fact, public politics requires a response to these handicaps to allow these people more complete lives. But here we've not even started. Today, we're going to look at physical challenges and how people are coping with them, what can be done to make their lives fuller. And I've got the gang with me and they are going to put their heart to this matter that really does touch the heart. And I've got from my left. Michael Aderounmu, Reuben Abati, Njide Kanedike, Cordilia Chinwoke

Now hem... you know... the... the challenge of discussing the handicaps that many of our citizens have to deal with cannot even begin all to take ah, ah shape unless we understand the level of neglect all of us have 
you know, cause to be ashamed of(.3) From this society to people who are physically challenged. Now, why is it that our society has not been able to pay as much attention to the challenges of our fellow citizens as perhaps other societies have managed to?

The excerpt above was an introduction of an episode of PG. the topic is typed in bold print for emphasis. If we examined the topic closely, we would realise that the host did not want to refer to those who are physically challenged in the society as handicaps or disables; that is why he chose the expression, "Physical Challenges". This expression would neither in any way belittle those involved nor embarrass them.

\section{Excerpt 11-ND2}

76. TH:

...Before we went on the break, we were aware of a certain young lady who got admission into University of Suxess and needed job or sponsor to settle her school bill. What I can't make out is, is she looking for the job here before she goes or is she looking for a job there, when she gets there well, okay there, alright Wole

77. PP:

I think she is going to have issues, for example, I know of Britain if you are doing your masters there, they allow you to take some hours to do part time work. I'm not sure if they do that to first degree. Secondly, hem....... Well I know about you for instance, I don't how many people come to you daily and asking you for money to go abroad; I've seen it here before and how many people can you help. My point is if you want to go, you have to design a plan yourself; it is either you go in search of your family members or your friends that can help you or you decide I'm going to look for work even if it is carrying concrete or water at a work site to raise money for this thing. I read it somewhere when Awo wanted to go to school abroad; he sought out a wealthy man, somebody he didn't really even know; he wrote out what he wanted to do and how he wanted to pay the money back he did, it took him so many years but he was actually able to get money from the man. So you have to imbibe the strategy and look around you because no one, no matter how wealthy they are, they will not just see you on the street and help. It is like walking on the road and thinking you will see 30,000 on floor. (sic) You know we all think like that.

78. $\mathrm{TH}:$

It is a bit painful because it is part of restructuring that must happen as Nigeria starts to recover from all these years of the military and the fall out and everything because if you find the usual way it will be if you are a student that is exceptional is thought either scholarship or.

I don't think she qualifies for any of these and to be frank I don't know how she gets a visa. Even if you've been admitted into a school abroad and you cannot prove that you can take care of your fees abroad, they will not give you a student visa. As you have said, there are two options: one, you have to look at people who are close to you, this is where churches and so on should actually play a role. If you have been a diligent worker at church or mosque there must be a body of elders who can look at your case and see if the church can help you at that foundation. If it is not down with your father or mother came up with you to the relative, it is easier than you go on your own I ...

Turns 77 and 78 were responses to a request from a lady who asked for sponsorship. The contributions of the guest and the host meant that "New Dawn" would not be able to help her. Instead of refusing her request directly, she was given options that would help her in obtaining sponsorship elsewhere.

\section{Conclusion}

Our findings revealed that out of the four maxims of cooperation, the maxim of quality was the most flouted as we recorded a 70\% flouts which was responsible for lots of interruptions from other participants. Although some of the flouts were meant to spice up discussions, they ate into the time allocated for the show. The quality maxim was always observed as the integrity of the guests and credibility of the talk show would determine the success of the show as regards the number of viewers. Flouts of relation were observed to have arisen out of sentiments and emotional outbursts. It was always important that participants kept to the topic of discourse. Despite all efforts made at being polite, a number of face threatening acts were observed. However, cooperation and politeness are important features of television discourse as the success of a programme depends on how well the host and participants observed the maxims of cooperation and the principles of politeness during discussions. 


\section{References}

Andersson, L. M., \& Pearson, C. M. (1999). Tit for tat'? The spiralling effect of incivility in the workplace. Academy of Management Review, 24, 452-471.

Brennan, S. E., \& Ohaeri, J. O. (1999). Why do electronic conversations seem less polite? The costs and benefits of hedging. Proceedings, International Joint Conference on Work Activities, Coordination, and Collaboration (WACC '99) (pp. 227-235). San Francisco, CA: ACM. http://dx.doi.org/10.1145/295665.295942

Brown, P., \& Levinson, S. C. (1987). Politeness: Some universals in language usage. New York: Cambridge University Press.

Carson, C. L., \& Cupach, W. R. (2000). Facing corrections in the workplace: The influence of perceived face threat on the consequences of managerial reproaches. Journal of Applied Communication Research, 28, 215-234. http://dx.doi.org/10.1080/00909880009365572

Cupach, W. R., \& Carson, C. L. (2002). Characteristics and consequences of interpersonal complaints associated with perceived face threat. Journal of Social and Personal Relationships, 19, 443-462. http://dx.doi.org/10.1177/0265407502019004047

Cutting, J. (2003). Pragmatics and Discourse. London: Routledge.

Earley, P. C. (1997). Face, harmony, and social structure: An analysis of organizational behavior across cultures. London: Oxford University Press.

Goffman, E. (1967). Interaction ritual: Essays on face-to-face interaction. Oxford, England: Aldine. (1986). Frame Analysis. Boston: Northeastern U. Press.

Grice, H. P. (1975). Logic and Conversation. In P. Cole \& J. Morgan (Eds.), Syntax and Semantics, 3, 41-58. New York: Academic Press.

Grundy, P. (2000). Doing Pragmatics. London: Arnold Publishers.

Gumperz, J. (1990). Conversational Cooperation in Social Perspective. In Meacham, M., Reinman, S., Sutton, L.A. (Eds.), Proceedings of the Sixteen Annual Meeting of the Berkeley Linguistics Society, February 16-19, 1990: General Session and Parasession on the Legacy of Grice. Kira Hall, Berkley: Berkley Ling Society.

Keltner, D., \& Buswell, B. N. (1996). Evidence for the distinctness of embarrassment, shame, and guilt: A study of recalled antecedents and facial expressions of emotion. Cognition and Emotion, 10, $155-171$. http://dx.doi.org/10.1080/026999396380312

Keltner, D., \& Buswell, B. N. (1997). Embarrassment: Its distinct form and appeasement Functions. Psychological Bulletin, 122, 250-270. http://dx.doi.org/10.1037/0033-2909.122.3.250

Keltner, D., \& Haidt, J. (1999). Social functions of emotions at four levels of analysis. Cognition and Emotion, 13, 505-521. http://dx.doi.org/10.1080/026999399379168

Keltner, D., \& Anderson, C. (2000). Saving face for Darwin: The functions and uses of embarrassment. Current Directions in Psychological Science, 9, 187-192. http://dx.doi.org/10.1111/1467-8721.00091

Lee, F. (1993). Being polite and keeping MUM: How bad news is communicated in organizational hierarchies. Journal of Applied Social Psychology, 23, 1124-149. http://dx.doi.org/10.1111/j.1559-1816.1993.tb01025.x

Leichty, G., \& Applegate, J. L. (1991). Social-cognitive and situational influences on the use of face saving persuasive strategies. Human Communication Research, $451-484$. http://dx.doi.org/10.1111/j.1468-2958.1991.tb00240.x

Linde, C. (1988). The quantitative study of communicative success: Politeness and accidents in aviation discourse. Language in Society, 17, 375-399. http://dx.doi.org/10.1017/S0047404500012951

Lindsley, S. L., \& Braithwaite, C. A. (1996). You should wear a mask: Facework norms in cultural and intercultural conflict in maquiladoras. International Journal of Intercultural Relations, 20, $199-225$. http://dx.doi.org/10.1016/0147-1767(96)00002-8

Metts, S. (1997). Face and facework: Implications for the study of personal relationships. In S. Duck (Ed.), Handbook of personal relationships: Theory, research and interventions (2nd ed., pp. 373-390). Chichester, UK: Wiley.

Odebunmi, A. (2003). Pragmatic Features of English Usage in Hospital Interactions Amongst Medical Practitioners and Patients in South-Western Nigeria. Ph.D. Thesis. Department of English. Obafemi Awolowo University, 
Ile-Ife. xvii +310

Odebunmi, A. (2005). The Context of Hospital Conversational Interactions in Southwestern Nigeria. Journal of Nigeria English Studies Association, 11(I).

Pan, Y. (2000). Politeness in Chinese Face Face Interaction. Stamford CT: Ablex Publishing Corporation.

Pearson, C. M., Anderson, L. M., \& Porath, C. L. (2000). Assessing and Attacking Workplace Incivility. Organizational Dynamics, 29, 123-137. http://dx.doi.org/10.1016/S0090-2616(00)00019-X

Roloff, M.E., \& Douglas, E. C. (1985). Conversational Profit-seeking: Interaction as Social Exchange. In Richard L. Street \& Joseph N. Cappella, (Eds.), Sequence and Pattern in Communicative Behaviour. London: Edward Arnold, 161-89.

Scollon, R., \& Scollon, S.W. (2003). Discourses in Place: Language in the materials world. London: Routledge. http://dx.doi.org/10.4324/9780203422724

Sisson, C. (2007). Computer Mediated Communication Project 05-817.

Spekman, Nancy J. (1983). Verbal Communication and Role-Taking: An Analysis of the use of Deictics. In Robert J. Di Pietro, William Frawley \& Wedel Alfred, (Eds.), The First Delaware Symposium on Language Studies: Selected Papers. Newark: U of Delaware Press, 168-86.

Ting-Toomey, S., \& Cocroft, B.-A. (1994). Face and facework: Theoretical and research issues. In S. Ting-Toomey (Ed.), The challenge of facework: Cross-cultural and interpersonal issues. Albany, NY: State University of New York Press, 307-340. 